\title{
The growing incidence of cancer: Role of lifestyle and screening detection (Review)
}

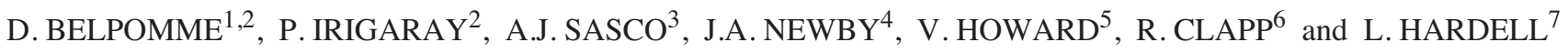 \\ ${ }^{1}$ Department of Medical Oncology, European Hospital Georges Pompidou (HEGP), University of Paris, F-75015 Paris; \\ ${ }^{2}$ Cancer Research Center, Association for Research and Treatments Against Cancer (ARTAC), F-75015 Paris; ${ }^{3}$ INSERM, \\ U 593 (Epidemiology for Cancer Prevention), F-33076 Bordeaux Cedex, France; ${ }^{4}$ Developmental Toxico-Pathology \\ Research Group, Department of Human Anatomy and Cell Biology, The Sherrington Buildings, University of Liverpool, \\ L69 3GE; ${ }^{5}$ Bioimaging Research Group Centre for Molecular Bioscience, University of Ulster, Coleraine BT52 1SA, UK; \\ ${ }^{6}$ Department of Environmental Health, Boston University School of Public Health, Boston, MA 02118, USA; ${ }^{7}$ Department \\ of Oncology, University Hospital, Örebro and Department of Natural Sciences, Örebro University, Örebro, Sweden
}

Received December 15, 2006; Accepted February 15, 2007

\begin{abstract}
The increasing incidence of a variety of cancers after the Second World War confronts scientists with the question of their origin. In Western countries, expansion and ageing of the population, as well as progress in cancer detection using new diagnostic and screening tests cannot fully account for the observed growing incidence of cancer. Our hypothesis is that environmental factors play a more important role in cancer genesis than it is usually agreed: i) over the last 2-3 decades, alcohol consumption and tobacco smoking in men have significantly decreased; ii) obesity is increasing in many countries, but the growing incidence of cancer also concerns cancers not related to obesity nor to other lifestyle-related factors; iii) there is evidence that the environment has changed over the same time scale as the recent rise in cancer incidence, and that this change included
\end{abstract}

Correspondence to: Professor D. Belpomme, ARTAC, 57-59 rue de la convention, 75015 Paris, France

E-mail: artac.cerc@wanadoo.fr

Abbreviations: CYP450, cytochrome P450; DNA, deoxyribonucleic acid; HAA, heterocyclic aromatic amines; HCC, hepatocellular carcinoma; HIV, human immunodeficiency virus; HNPCC, hereditary non-polyposis colorectal cancer; IARC, International Agency for Research on Cancer; INSEE, Institut national de la Statistique et des Études Économiques; InVS, Institut national de Veille sanitaire; sNCI, National Cancer Institute USA; OECD, Organization for Economic Cooperation and Development; PAF, Population Attributable Fraction; PAH, Polycyclic Aromatic Hydrocarbons; SEER, Surveillance, Epidemiology and End Results; UADT, Upper Aero-Digestive Tract; WHO, World Health Organization

Key words: alcohol, ageing, cancer, carcinogenesis, dietimbalance, fetus-susceptibility, genetic-susceptability, obesity, screening, tobacco-smoking the accumulation of many new carcinogenic factors in the environment; iv) genetic susceptibility to cancer due to genetic polymorphism cannot have changed over one generation and actually favours the role of exogenous factors through geneenvironment interactions; $v$ ) age is not the unique factor to be considered since the rising incidence of cancers is seen across all age categories, including children; vi) the fetus is specifically vulnerable to exogenous factors. A fetal exposure during a critical window period may explain why current epidemiological studies may be negative in adults. We therefore propose that the involuntary exposure to many carcinogens in the environment contributes to the rising trend in cancer incidence.

\section{Contents}

1. Introduction

2. Role of lifestyle factors in inducing cancers

3. Epidemiological arguments in favour of the role of the environment in the current growing incidence of cancer

4. Modifications of endogenous factors cannot account for the currently growing cancer incidence

\section{Introduction}

The overall incidence of cancer is increasing worldwide. Since 1990, global cancer incidence has risen by $19 \%$, while mortality rates from all cancers fell by $17 \%$ in persons aged 30-69 and rose by $0.4 \%$ in those aged 70 and over (1-3). With an estimated 2.9 million new cases and 1.7 million deaths each year cancer remains an important public health problem in Europe (4). In France since 1980, cancer incidence rate has risen by $30 \%$, as in many other countries (Fig. 1). In the USA, as in several other developed countries, $50 \%$ of men and over $30 \%$ of women can expect to develop cancer during their lifetime. In the 1950s the lifetime risk was about 1 in 4 (5). A similar evolution is observed in many countries in 


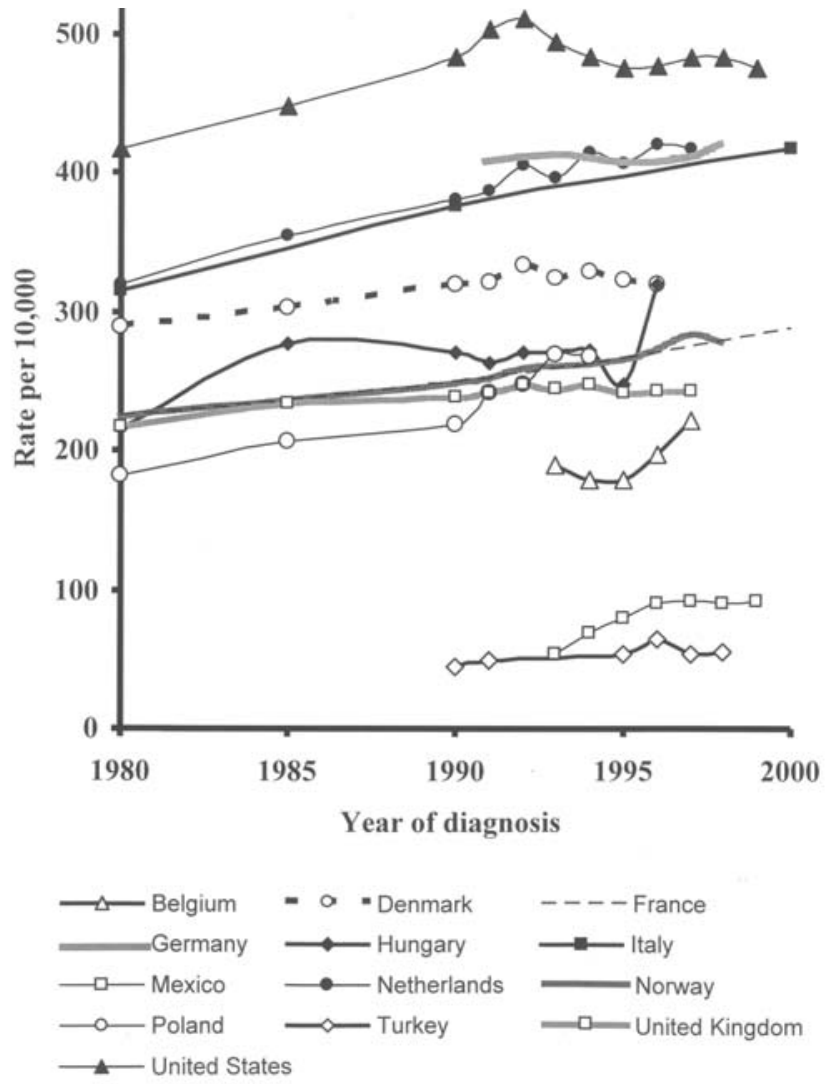

Figure 1. Cancer incidence rates in developed countries. (adapted from OECD health data, 2004).

Europe. In Western countries, although mortality has declined, cancer is now the second leading cause of death overall and the leading cause of death under the age of 75. According to WHO, worldwide cancer burden is set to increase by as much as $50 \%$ by the year 2020 , unless further preventive measures are put into practice (6).

There are currently two opposite interpretations of the growing incidence of cancer. The first one considers that environmental pollutants can only make a minor contribution to overall cancer incidence changes and therefore that increase in the size and ageing of the population, lifestyle influences such as smoking, alcohol consumption and diet, and new progress in diagnosis and screening procedures can explain the current increased cancer incidence (7-9). Conversely, the second interpretation, considering that these arguments are not sufficient, estimates that in addition to these factors, there is a contribution from the environment and that involuntary exposure to diverse pollutants may be involved $(5,10-13)$. The definition of environment varies according to authors. Usually, it refers to the physical, chemical and biotic factors that act upon an individual, and therefore include social and cultural conditions. Geneticists consider all factors that are not innate and therefore, include lifestyle-related factors among environmental factors. We focus here on physical, chemical and biological agents, which may be present in the surroundings of individuals. By contrast, behavioural habits such as smoking, alcohol consumption and diet are excluded from the definition (14).

In a recent report, mortality from 12 types of cancer in 7 World Bank regions were attributed to 9 risk factors, among
Table I. Percentage age of cancers attributable to alcohol and smoking. ${ }^{\mathrm{a}}$

\begin{tabular}{lcc}
\hline & Men $(\%)$ & Women $(\%)$ \\
\hline Alcohol-related cancers & & \\
Oropharynx & 21 & 8 \\
Oesopharynx & 14 & 6 \\
Liver & 18 & 12 \\
Larynx & 21 & 13 \\
Female breast cancer & - & 3 \\
& & \\
\hline Smoking-related cancers & & \\
Oropharynx & & 1 \\
Oesopharynx & 57 & 46 \\
Stomach & 54 & 11 \\
Anus & 14 & 41 \\
Pancreas & 48 & 19 \\
Larynx & 24 & 66 \\
Lung & 73 & 77 \\
Uterus & 84 & 10 \\
Cervix & - & 19 \\
Vulva & - & 4 \\
Penis & - & - \\
Bladder & 30 & 21 \\
Renal parenchyma & 43 & \\
Renal pelvis & 28 & \\
\hline
\end{tabular}

${ }^{a}$ According to English et al (15).

which 5 result from lifestyle, 2 from viral infection and 2 from air pollution (3). However, all together, these 9 risk factors account for $39-41 \%$ of all cancers. So, they are not representative of all presumed risk factors involved in carcinogenesis. The present overview focuses on Western countries. It aims at analyzing new environmental risk factors, discussing the plausibility of their causal effect in the genesis of cancers. We propose that the involuntary exposure to many carcinogens in the environment contributes to the rising trend in cancer incidence in high-income countries.

\section{Role of lifestyle factors in inducing cancers}

It is well agreed that smoking and to a lesser extent alcohol consumption, diet imbalance, obesity and lack of physical exercise are contributing factors to cancer in high-income countries. We analyze these factors and discuss their pertinence and magnitude of effect.

Tobacco smoking. Smoking is indeed a major concern. Because tobacco smoke and tar contain mutagenic substances, including Polycyclic Aromatic Hydrocarbons (PAH) and nitrosamines, smoking is a major factor contributing to human carcinogenesis and one of the best determined (Table I). As underlined by many authors, smoking is a risk factor for several types of cancers, mainly lung cancers and cancers of the upper aero- 
digestive tract (UADT) (including cancers of the oral cavity, nasal cavities and sinuses, pharynx and larynx), but also, to a certain extent, esophagus, stomach, pancreas, liver, bladder, kidney and cervical cancers, as well as myeloid leukemia $(15,16)$. Because many of these cancers are associated with a poor prognosis, smoking remains a major cause of cancer mortality. In high-income countries, the mean Population Attributable Fraction (PAF) for tobacco smoking in both sexes combined is estimated to be $25-30 \%$ of the overall cancer mortality (17). However, because many of these cancers are generally of poor prognosis, PAF related to overall cancer incidence is lower, probably in the order of $20-25 \%$ (12). Indeed a major question remains to determine the different factors which contribute to the approximately $70-75 \%$ of cancers not related to smoking.

Alcohol consumption. In contrast with PAH and other carcinogenic molecules found in tobacco smoke and tar, ethyl alcohol is not per se a molecule with mutagenic properties, but acts mainly as a cocarcinogen. On the basis of epidemiological data, alcohol has nevertheless been classified as a human carcinogen (18). Indeed alcohol can potentiate the carcinogenic effects associated with smoking or other factors (19) through a cocarcinogenic effect, which accounts for amplification of UADT and esophageal cancer incidence. However, an elevated risk of UADT cancers in the absence of tobacco smoking and of non-tobacco-associated cancers has been observed (Table I, 18). These observations strongly suggest that in such cases, alcohol consumption may be associated with other carcinogenic factors. The mechanism of action of ethanol is not clear. In addition to its predominant cocarcinogenic effect, ethanol has been thought to be associated with some promoting effect. Here we clearly distinguish cocarcinogens from promoters. A cocarcinogen is a molecule which can activate or enhance the action of a carcinogen be it a mutagen or a promoter (20). On the other hand, a promoter is a molecule which stimulates the division of cells and may promote loss of differentiation and apoptosis induction, be the cells mutated or not (21). Among the cocarcinogenic effects of alcohol are the depletion of detoxifying molecules such as glutathione and the induction of the hepatic cytochrome P450 2E1 (CYP2E1) enzyme, leading to the activation of procarcinogens into carcinogens $(22,23)$. By contrast, a promoting effect for alcohol, through immunosuppression induction has been suggested (24). However, this hypothesis has never been validated through pertinent toxicological and epidemiological studies. In addition, because induction of CYP2E1 in the liver may result in the metabolising of ethanol into acetaldehyde, thus leading to the production of mutagenic free radicals, it has been postulated that ethanol may also contribute to initiate specifically hepatocellular carcinoma (HCC) through mutagenesis (25). Yet, this hypothesis needs to be validated. Furthermore, due to a decrease in alcohol consumption over the last 20 years, PAF for alcoholrelated cancers is only $4 \%$ in high-income countries (3). We therefore conclude that the presumed carcinogenic effect of ethanol needs to be clarified by new toxicological and epidemiological studies, and that overall, because of its trends to decrease, alcohol consumption cannot be a factor related to the recent growing incidence of cancers.
Diet. Several studies have shown that in highly developed countries, food intake imbalance, rich in calories and animal fat and low in fibre, in other words, rich in red meat and poor in fruit and vegetables, is a factor that fosters the occurrence of some cancers (colon, prostate, endometrium and breast) and conversely that high intake of fruits and vegetables has a protective anticancer effect $(26,27)$. Migrant studies strongly suggest that lifestyle-related diets can affect the genesis of the aforementioned cancers $(2,28-30)$. They cannot however rule out the possibility of other associated causal factors. A common interpretation is that increased animal fat intake, rich in polyunsaturated fatty acids, can generate mutagenic free radicals by increasing oxidative stress (31), while diets rich in fruit and vegetables, because they contain many natural antioxidants, can yield an anticancer protection (32-34). We question the magnitude and interpretation of these presumed effects. PAF for cancers related to low fruit and vegetable intake is estimated to be only $3 \%$ of cancer mortality in Western countries (3). Furthermore, experimental animal studies have not proven that high fat diet can initiate cancers, but rather that fatty diets can be associated with a cocarcinogenic effect through the induction of the cytochrome P450 system (35). Identification of mutagenic substances associated with cooking of high fat diet has been the object of many efforts. Pyrolysis of aromatic amino-acids and of fatty acids associated with grilled meat has been suspected to be involved in mutagenesis, leading to the hypothesis that heterocyclic aromatic amines (HAAs) and polycyclic aromatic hydrocarbons (PAH) respectively could play a role in cancer initiation (36-38). Some epidemiological studies support this hypothesis, whereas others do not. Such discrepancy may depend on genetic susceptibility (39). Because these studies concern specific selected samples of the population, a major question is to what extent grilled meat (containing HAAs and/or PAH) could impact carcinogenesis in the general population. Furthermore, on the basis on epidemiological and biological data, the role of dietary fat in carcinogenesis is not so clearly defined as usually agreed. Many epidemiological studies testing the presumed role of animal fat in the genesis of cancer are controversial (40-42). An explanation could be that these studies have not been evaluated by taking into account genetic polymorphism and/or continuous induction of CYP450 together with duration of exposure. Although it has been shown that animal fat intake may be associated with colorectal cancer occurrence, it has never been proven that fat per se can initiate carcinogenic effects $(43,44)$. In fact, because diets rich in fatty acids are generally associated with low fruit and vegetable intake, it is indeed quite difficult to disentangle the two effects in epidemiological studies. While it is suggested that food imbalance may act through a direct cocarcinogenic or even indirect promoting mechanism, the hypothesis that fibre in a well-balanced diet (rich in fruit and vegetables) plays a protective role by inhibiting the effect of carcinogens possibly contaminating food or being added to it, is put forward $(45,46)$.

Overweight, obesity and sedentariness. Overweight, obesity and sedentariness have been incriminated as risk factors for cancer $(47,48)$. Recent studies in the USA have shown that 
Percent of population, daily smokers

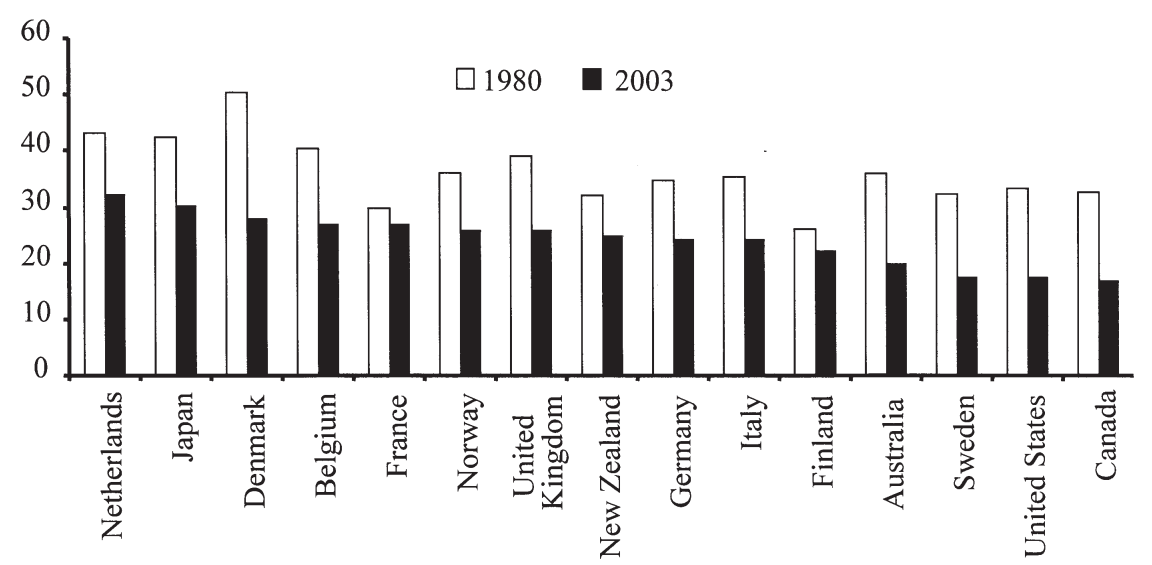

Figure 2. Trend for daily smoking in the adult population (aged over 15) in 1980 and 2000 in developed countries (adapted from OECD health data, 2005).

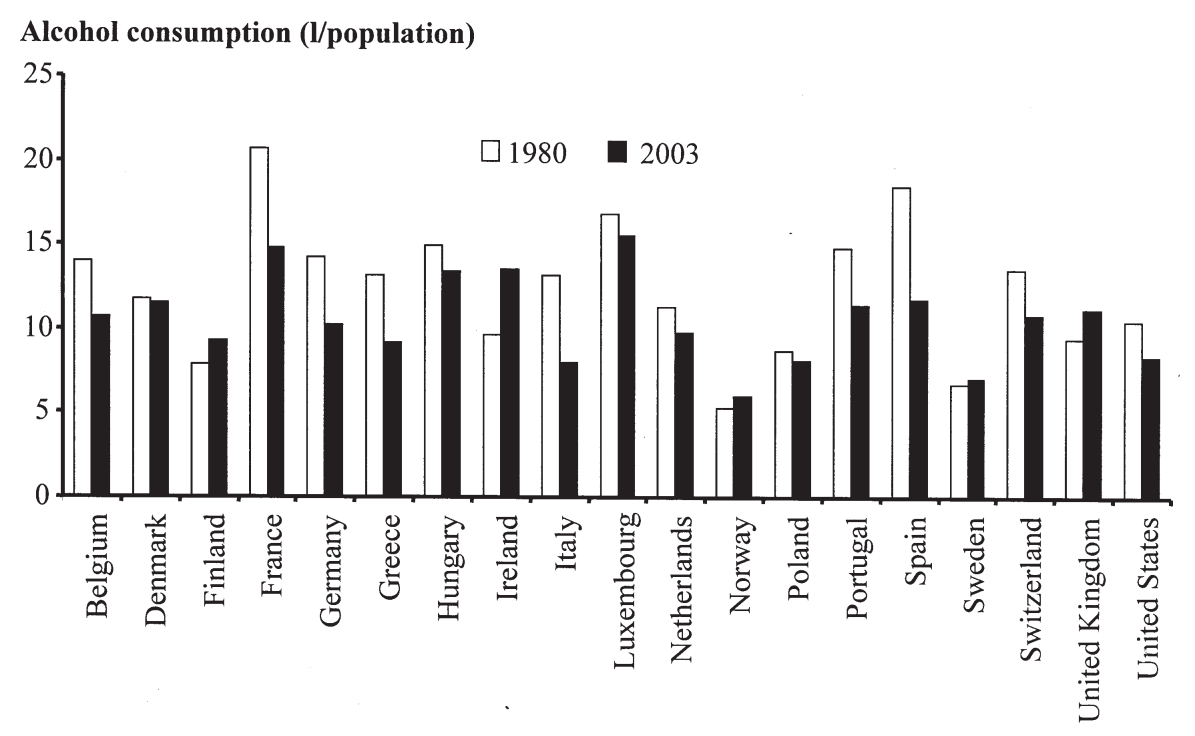

Figure 3. Trend for alcohol consumption (litres per population aged over 15) between 1980 and 2000 in developed countries (adapted from OECD health data, 2005).

obesity associated with some cancers can worsen mortality (49). Indeed, because obesity by itself increases mortality, these studies do not prove that obesity per se is a factor involved in cancer mortality. However, in many studies, obesity was found to be associated with an increased incidence of several cancer types $(50,51)$ with the exception of lymphoma (52) and childhood cancers (53). Consequently, aside from these cancers, a recent hypothesis is that the observed increase of incidence of several cancer types, such as breast, colon, liver or kidney cancers may be partially due to obesity (54). However, in Western countries, PAF for obesity-associated cancers and for cancers associated with physical inactivity are only $3 \%$ and $2 \%$ respectively for cancer mortality (3). Thus, as for fatty diets, the role of obesity in carcinogenesis is not clear. Indeed a promoting mechanism whereby obesity could be a risk factor through a modification of the hormonal milieu remains hypothetical (48). Moreover, it has never been demonstrated that excess weight and obesity can initiate cancer. They can, however, indirectly contribute to cancer genesis through a progressive accumulation of chemical carcinogens in adipose tissue. We have clearly shown that lipophilic organic xenomolecules such as benzo[a]pyrene can accumulate in adipose tissue (55) and therefore, that this tissue should be considered as a reservoir for lipophilic xenomolecules including persistent organic pollutants such as dioxins and PCBs (56) from which they are released into the plasma, where they can be detected at doses positively correlated with the body mass index (57). We have clearly demonstrated that benzo[a]pyrene can favor obesity in mice by impairing $\beta$-adrenergic stimulation of adipose tissue lipolysis (56). We therefore hypothesize that some carcinogenic molecules may be involved both in obesity and cancer genesis. Such mechanism seems to have been recently suggested for tributyltin an endocrine disruptor associated with carcinogenesis (58) which have been shown to increase adipose mass (59). Since obesity has been found to be associated with several types of cancer, our observation allows to consider that factors other than food intake imbalance and abnormal diet may be involved in carcinogenesis. In addition, a high number of molecules, rated as carcinogenic, probably carcinogenic or possibly carcinogenic to humans, belonging respectively to the IARC's groups $1,2 \mathrm{~A}$ and $2 \mathrm{~B}$ for the 


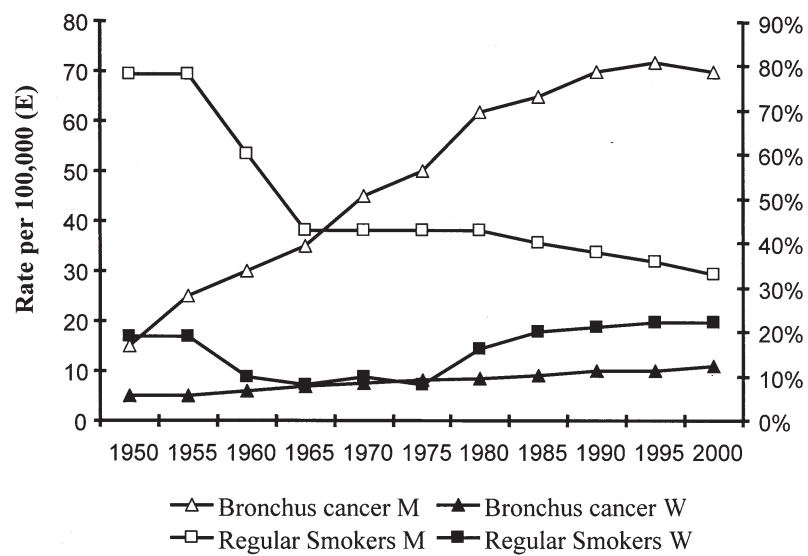

Figure 4. Lung cancer mortality rates in men and women between 1950 and 2000 in France, in relation to smoking (adapted from INSEE, 2006).

evaluation of carcinogenicity to humans (60), can bioaccumulate in the organism and may contribute also to carcinogenesis. We are therefore led to the conclusion that, in addition to classical lifestyle-related risk factors, other carcinogenic factors found in the environment could also play a major role in the genesis of cancers.

\section{Epidemiological arguments in favour of the role of the environment in the current growing incidence of cancer}

The interpretation of the currently growing incidence of cancer shows a divergence of opinions among experts. Some of them, referring to the initial study of Doll and Peto (61) and taking into account ageing of the population and the recent improvement of diagnostic and screening techniques, consider that the main causes of cancer are still related to our lifestyle and that the current growing incidence of cancer is due both to the increase of population life expectancy and the detection of small tumors, which normally will have never developed into symptomatic true cancers. Conversely, other experts referring to the most recent epidemiological and toxicological data emphasize environmental carcinogenic factors $(5,11-13)$. This is the issue we attempt to address hereby, based on epidemiological considerations.

Decrease in tobacco and alcohol consumption. The Doll and Peto study dates back to 1981 and is based on earlier US epidemiological data. Yet, since 1981, our environment has been greatly modified. Alcohol consumption has been in the decline in all countries except in Nordic countries, so it cannot explain the growing incidence of cancers in non-Nordic countries. In addition, smoking for men decreased in all countries (Figs. 2 and 3), so it cannot be a further explanation of the growing incidence of cancers. Though mortality due to lung cancer has increased in men since the last world war in many countries and more recently in women, at the same time tobacco consumption and the proportion of regular smokers have decreased in men in several developed countries, whereas it has progressively increased in women (62). This observation is worth discussing. The analysis in Fig. 4 shows that in France, increase in mortality due to lung cancer in men has slowed down since 1990 and currently tends to level

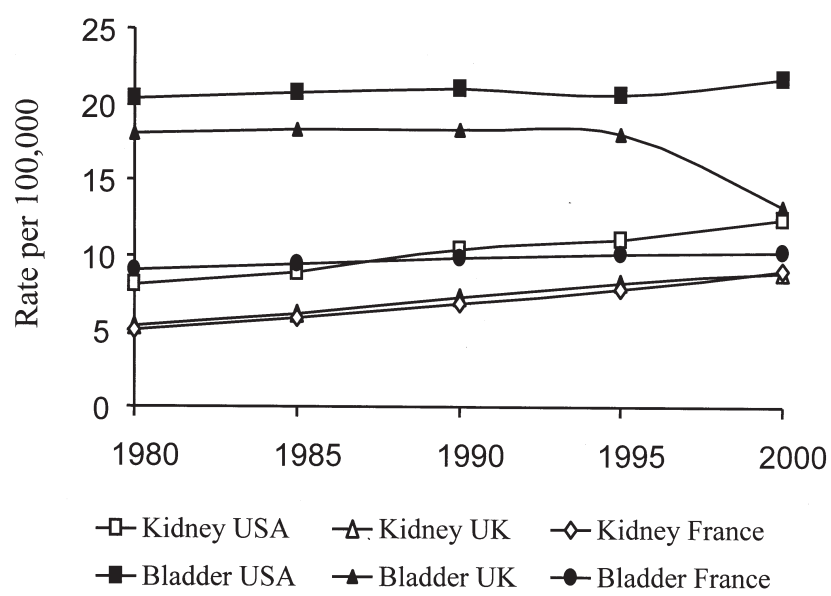

Figure 5. Incidence rates of bladder and kidney cancers between 1980 and 2000 in United Kingdom, USA and France. Rates are standardized and ageadjusted according to the 2000 US population for USA (adapted from SEER Cancer Statistics Review 1975-2003), age-standardized (Europe) for UK (adapted from Cancer Research UK) and age-standardized (World) for France (adapted from InVS, 2003).

off, which suggests that mortality could drop sharply in years to come, if a stringent policy against smoking is maintained, as any epidemiological translation of reducing smoking requires several decades before its health impact becomes apparent. This is indeed the case today in countries that have launched a real fight against smoking many years ago. However, because PAF for tobacco smoking-associated lung cancer mortality is approximately $90 \%$ for men and $70 \%$ for women in industrialized countries (63) and probably lower for incidence, i.e. in the order of $80 \%$ and $60 \%$ respectively, it clearly appears that lung cancers are not exclusively related to tobacco smoking (64-66). Likewise, recent epidemiological data concerning cancers partially related to tobacco smoking, such as bladder and renal cell carcinoma, need to be interpreted in the light of other causal factors. While over the last two decades, incidence of bladder cancer is decreasing in the UK, possibly because of a reduction of smoking, paradoxically it is increasing in France and is stable in the USA, although smoking is also decreasing (Figs. 2 and 5). A similar trend is observed with renal cell carcinoma. Incidence is growing in the UK, France and in the USA, while tobacco smoking is decreasing in these countries (Figs. 2 and 5). This strongly suggests that for kidney carcinoma as well as bladder carcinoma, carcinogenic factors other than smoking have recently emerged. A similar paradoxical picture exists for HCC. Although the incidence of UADT and esophagus alcohol-related cancers have markedly declined over the past decades in many European countries including France (Table I, Fig. 6), mainly due to a decrease in alcohol consumption, incidence of HCC has increased. The currently growing incidence of $\mathrm{HCC}$ could therefore be the consequence of other oncogenic factors, such as viral hepatitis B and C $(67,68)$ and/or chemical carcinogens $(69,70)$.

Finally, a basic observation is that the incidence of and mortality from cancers strongly related to tobacco and/or alcohol consumption have been decreasing over the last two decades, while the incidence of cancers not related to tobacco and/or alcohol consumption or to obesity, have been increasing 


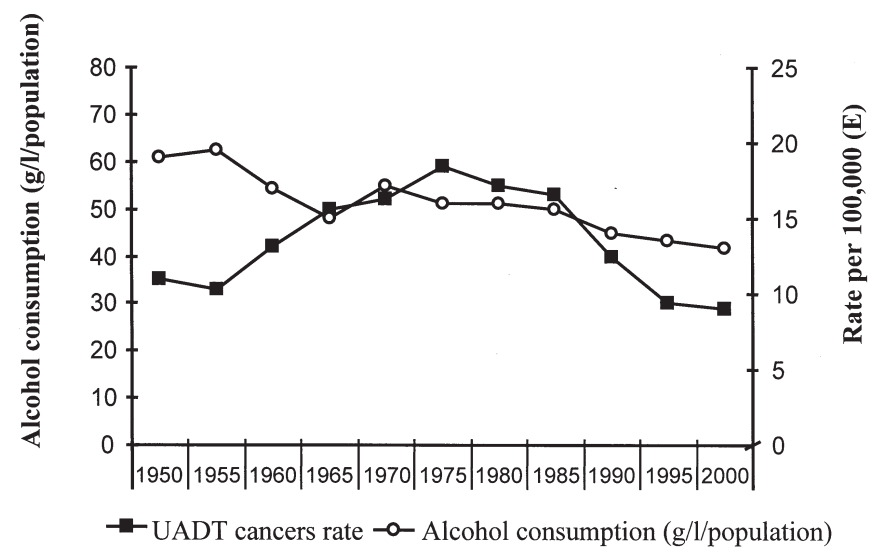

Figure 6. Incidence rates of upper aerodigestive tract (head and neck, lung, and esophagus) cancers between 1950 and 2000 in France in relation to alcohol consumption in France. (adapted from Ledermann 1956 (161), Nizard 2000 (162), INSEE 2006).

(Figs. 1 and 7). This figure reversal characterizes many industrialised Western countries in Europe and in the USA, where the incidence of cancers non-related or weakly related to alcohol and/or tobacco consumption exists $(71,72)$. This increasing incidence and thus the increased risk of cancer, mainly concerns breast cancer in women and prostate cancer in men, but also thyroid cancer, as well as non-lifestyle related cancers including melanoma, mesothelioma, brain tumors, leukemias and lymphomas in adults of both sexes, testicular cancers in young adults and childhood cancers (Figs. 1 and 7).

Impact of new diagnostic and screening methods. Over the last two decades, in Europe and North America, the mean estimated number of yearly cancer cases has approximately doubled for breast cancer $(73,74)$, more or less doubled for prostate cancer $(74,75)$ and more or less doubled for thyroid cancer (76) depending on the country considered. Simultaneously, progress in diagnostic and screening techniques including mammography for breast cancer, cervical smears for cervical cancer, PSA for prostate cancer and ultrasonography for thyroid cancer has emerged allowing detection of small tumors for these four cancer categories (77-80). Clearly, the marked rise in incidence of these cancers with the exception of cervical cancers which has drastically declined over the last decades (81) may be due in part to the detection of latent tumors which may have never progressed into symptomatic cancers $(76,82,83)$. However, although this incidence increase can be partly explained through the recent generalization of screening tests, we assume that other factors do occur for the following reasons: i) with the exception of some very slightly invasive and slowly progressing cancers, any truly invasive cancer almost always converts into a symptomatic disease and consequently is recognized clinically. A significant number of cancers that were not screened 20 years ago were thus probably diagnosed, meaning that in the case of good cancer registries, there cannot be a deficit in reporting; ii) the current screening tests improve early detection of cancers and thus most probably improve prognosis. Indeed, screening for cancers which are detected at a really invasive stage (breast cancer for example) can only influence mortality. On the other hand, impact on reduced incidence can only be assumed for cancers screened at a pre-invasive stage (cervix and colon cancers for example). The current tests should therefore influence mortality rather than incidence unless one considers the possibility of numerous false positive tests, an hypothesis which cannot be substantiated, due to the systematic carrying out and analysis of tissue biopsies showing invasive cancers. This is the case in particular for prostatic cancer. Careful analysis of biopsies revealed that screened cases were associated with the same Gleason grading as non-screened cases, meaning
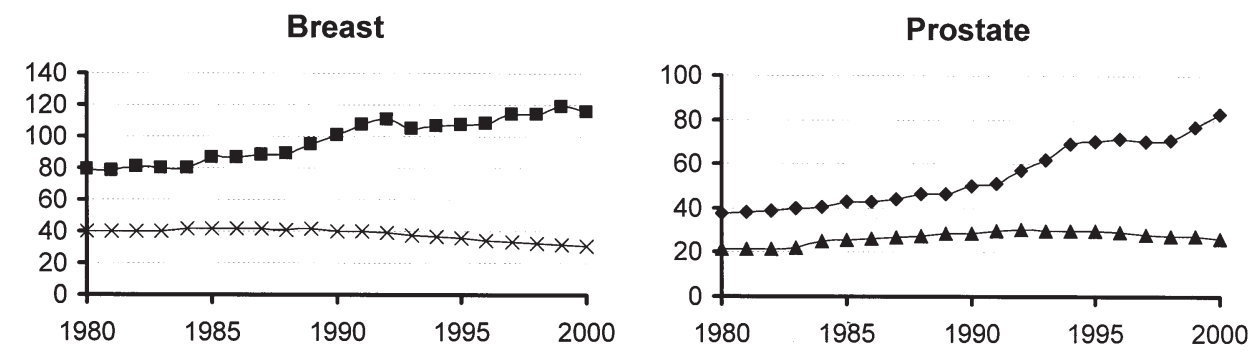

Bowel
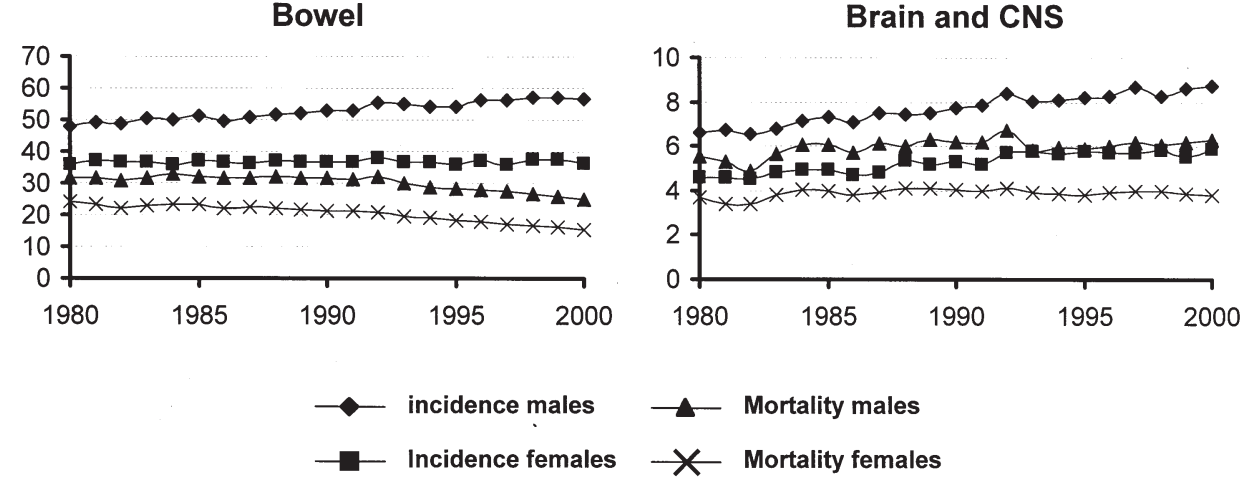

Figure 7. Incidence and mortality rates for different cancers (breast, prostate, bowel and brain and CNS) in UK, 1975-2003 (adapted from Cancer Research UK). 
Leukaemias

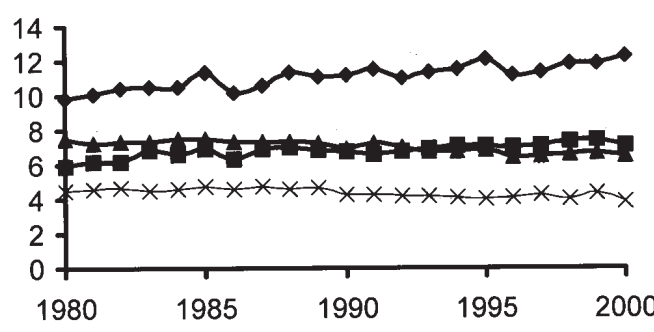

Children cancers

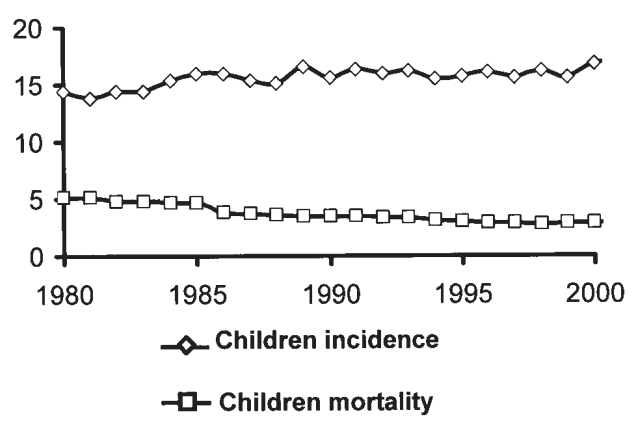

NHL

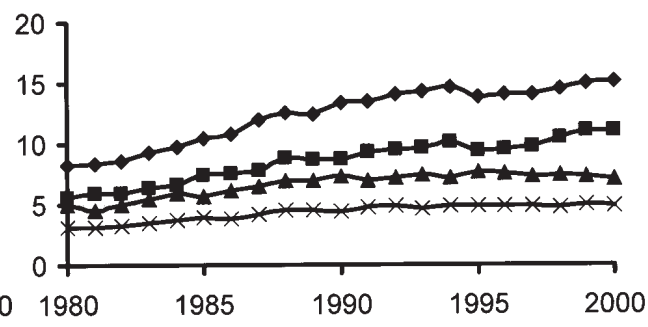

Figure 8. Incidence and mortality rates for different cancers (NHL and Leukaemia) in UK 1975-2003 (adapted from Cancer Research UK). Incidence and mortality rates for cancers in children and adolescents under the age of 20 in USA (1980-2000) (adapted from National Cancer Institute, Division of Cancer Control and Population Sciences. SEER Cancer Statistics Review, 1975-2003).

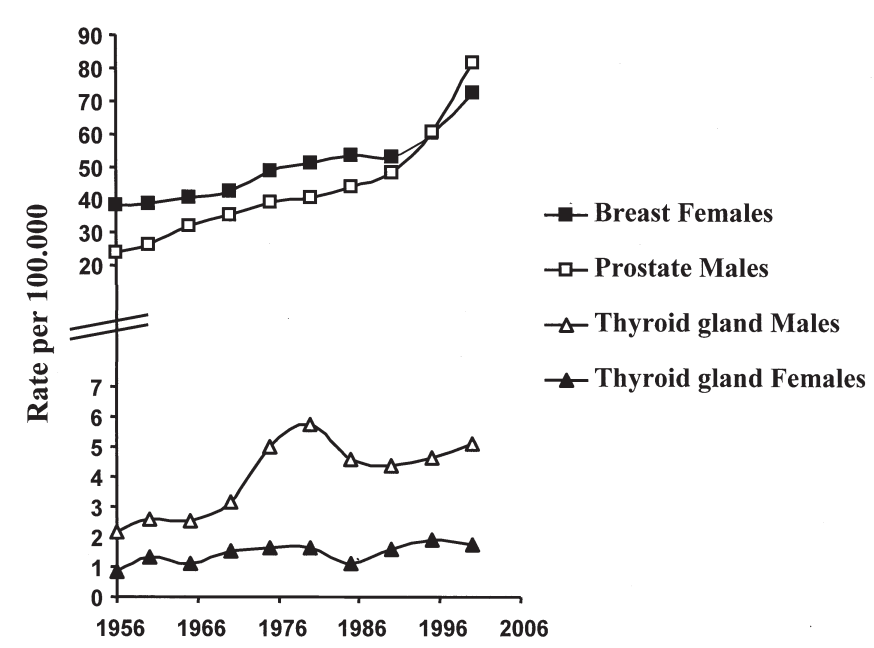

Figure 9. Incidence rates for breast, prostate and thyroid cancers since 1955 in Norway (adapted from Institute of Population-based cancer Research The Cancer Registry of Norway).

that screened cases carry the same histoprognosis as nonscreened cases (79); iii) consequently, as a result of screening, a clear decrease in mortality in countries that systematically used screening tests should have been expected. Unfortunately, except for cervical cancer, it is not the case. So, for breast carcinoma, since the use in the late 1980s of systematic screening in 16 European countries, where cancer incidence was increasing, cancer mortality is either stable or slowly decreasing (84). This indicates that part of the increased number of new screened cases was probably related to truly malignant cancers and that screening methods are not sufficient to eradicate cancer mortality. This emerging new concept has been recently debated $(85,86)$. In fact, screening can influence mortality in the detection of both invasive cancers and of pre-cancerous lesions $(87,88)$. In countries that did not use systematic, but rather opportunistic screening, breast cancer incidence is growing, while cancer mortality is either increasing or stable. This indicates that screening may not be efficient, but that the growing incidence of cancer is not related to precancerous or smoldering invasive cancers, but to truly malignant cancers (89); iv) in countries or regions where the incidence rates of breast, prostate or thyroid cancers have been historically low and where there has been no systematically performed screening test detection, increased incidence rates of these cancers is now observed $(2,75,90)$; v) in many countries, the increased incidence of these cancers is such that it is very unlikely that all new cases could be solely due to improvements in diagnosis and screening test procedures (Figs. 7 and 8); vi) a careful analysis of cancer registries of countries that have systematically collected all new cancer cases during a sufficiently long period, i.e. before and after the introduction of new screening tests supports this hypothesis: this is the case in Norway. Fig. 9 relates to the evolution of incidence rates for breast, prostate and thyroid cancers since 1955 . For breast and prostate cancers, one can individualize two different slopes of the curves, with a break point between 1992 and 1993 which may correspond approximately to the general use of mammography and PSA detection. It is worthy of note that before the introduction of these tests, prostate cancer cases had doubled in number and breast cancer cases nearly doubled. A similar interpretation can be used for thyroid cancers. Their progressive increasing incidence starts a long time before the general use of ultrasonography for their detection; vii) finally, the overall incidence increase concerns 
cancers for which no screening test has been developed over the last 20 years: this is the case for testicular cancers as well as for melanoma, lymphoma, leukemia and childhood cancers. Therefore, we theorize that the increased risk of cancer corresponds to a genuine phenomenon from a biological, epidemiological, medical and public health point of view.

\section{Modifications of endogenous factors cannot account for the currently growing cancer incidence}

Before considering our hypothesis plausible according to which the involuntary exposure to many carcinogens in the environment greatly contributes to the genesis of cancer, a basic question is to examine whether endogenous factors might have been implicated to account for the current growing incidence of cancer and to what extent they might have been involved. This issue is thus worth addressing at a genetic and biological level and consequently focuses more precisely on expanded life expectancy and ageing, as the growing burden of cancer in elderly people could explain the growing incidence of cancer.

Genetic versus environmental influences. Cancer is generally recognized as a multistage disease involving accumulation of a critical number of mutations within a stem cell (91). The discovery of oncogenes, tumor suppressor genes, DNA repair genes and cancer susceptibility genes has led to the concept that carcinogenesis is a pure endogenous genetic process $(92,93)$. Clearly, this concept has to be revised, because causation of cancer must be distinguished from its consequences, i.e. the disease itself. Indeed, it has become increasingly evident that due to gene-environment interactions (39), cancer is causally an environmental disease. Two elegant studies documented this new scientific paradigm. Data based on the analysis of co-occurring cancer incidence in a cohort of identical twins have demonstrated that environmental rather than genetic factors predominate in the aetiology of cancer. Theoretically a high level of co-occurrence would have revealed that inheritance is more influential than environmental factors in the causation of cancer. But it is not the case. The study showed that the concordance rate of cancer among identical twins was rather low, indicating that non-genetic influences predominate (94). Moreover, estimation of the relative proportion of genetic and environmental influences for each specific cancer, using a structural equation model, showed that for all cancer types, except thyroid cancers, environmental factors (including lifestyle-factors) predominated (95). It appears therefore, that environmental factors prevail in the aetiology of cancers and consequently that inherited genetic factors are not involved in the current growing incidence of cancer.

Innate and acquired susceptibility to cancer. In order to further examine the hypothesis according to which endogenous factors could be considered, it is necessary to question whether the growing incidence of cancer may have resulted from the occurrence of specific inherited mutations of susceptibility genes or from acquired somatic susceptibility within the general population. It is clearly established that in addition to their mutagenic effects, radiation, viruses and chemicals can be cancer promoters via immunosuppression induction. Such a mechanism of acquired susceptibility to cancer is exemplified in selected specific population samples including patients treated with immunosuppressive drugs for organ transplantation $(96-99)$, irradiated people $(100,101)$ or people with HIV infection (102). We do not know to what extent environmental immunosuppressive factors and particularly immunosuppressive chemicals could contribute to acquired susceptibility to cancer within the general population and therefore to what extent, these acquired environmental factors may have been implicated in the current growing incidence of cancer. On the other hand, inherited factors accounting for cancer susceptibility include theoretically specific oncogenes as well as genes involved in the activation or detoxification of carcinogens and repair of DNA damage (39). Three types of arguments discredit the hypothesis according to which an increase in inherited genetic susceptibility could have occurred, accounting for the growing incidence of cancer: i) only a small proportion of cancer follows a Mendelian pattern of inheritance $(103,104)$. Familial cancers arising as a result of highly penetrant mutations be they associated or not with hereditary cancer predisposition syndromes, are unlikely to account for more than $10-15 \%$ of all childhood cancers meaning that they represent no more than $0.2 \%$ of the total cancer burden $(105,106)$. In addition, inherited tumor suppressor oncogenes, such as BRCA1 and BRCA2 genes in patients with familial breast carcinoma (107) or other inherited susceptibility genes, such as hMSH2, hMLH1, hPMS1, hPMS2 and hMSH6 genes, in Hereditary NonPolyposis Colorectal Cancer (108) are relatively rare (109) and taken together account for less than $5 \%$ of cancers (110). Moreover, despite considerable efforts to identify common less penetrant susceptibility genes for cancer discovery such genes are disappointing (111); ii) by contrast, a more likely situation is that cancers develop as a result of exposure to risk factors in genetically susceptible individuals (112). Indeed, inherited genes that encode enzymes involved in the activation or detoxification of exogenous carcinogenic factors are much more frequent. These genes are polymorphic in nature, meaning that they are a common variant of the enzyme genes $(39,113)$. As a consequence of polymorphism, individual variations in the metabolism of carcinogens account for differences in susceptibility to cancer and could thus impact on the population attributable risk for cancer. Polymorphism has resulted from mutations, which have survived and passed through generations (39). However, it is theoretically and practically impossible to believe that in one generation (25 years), genetic polymorphism would have been modified such that it could have increased so greatly the population's genetic susceptibility (104); ii) Moreover, while the previous exceptional childhood cancers associated with Mendelian pattern of inheritance are purely related to inherited penetrant endogenous mutations, for all the other inherited cancers, genetic susceptibility just increases the risk of cancers related to exogenous and especially environmental factors $(94,114)$. For example, this is the case for women having one or the other inherited tumor suppressive susceptibility gene BRCA1 or BRCA2. The risk of having breast cancer at age 50 is $24 \%$ for those born before 1940 , while it is $67 \%$ for those born later (107). This means that 
since the last world war, a new phenomenon occurred, whether it is related to lifestyle modifications (hormone treatments, later age at first pregnancy, increased number of women with no pregnancy etc.) or to environmental changes.

Ageing and extended life expectancy. A major and recurring counter-argument to the environmental concept whereby the current growing incidence of cancer is due to changes in our environment is that we are living longer and cancer incidence increases with age. There is no doubt that life expectancy has been increasing for many decades in Western countries and that cancer incidence increases with age, thereby leading to an increased number of new cases and of deaths from cancer (115-121). The widely accepted opinion according to which extended life expectancy, i.e. increased age, is a major factor to explain the current increase in cancer incidence needs however to be clarified. Crude numbers of cancer burden, be it the number of new cases or the number of deaths are affected by changes in the population size and structure. For comparisons of populations over time, age-standardized rates need to be computed. Therefore age no longer plays a role when examining age-standardized rates and their trends over time or differences across populations. Moreover, from a biological standpoint, the role of ageing in the occurrence of cancer shall be discussed. A basic assumption, which supports the role of age, is that, according to the multistage theory proposed by Armitage and Doll in 1954 (122), people living longer have a greater chance of accumulating the critical number of mutations needed for cell transformation. Indeed the multistage somatic mutations theory is not incompatible with the rising incidence of cancer associated with increasing age, if we assume that many environmental factors are carcinogenic and cancer risk is clearly related to the duration of exposure to exogenous carcinogens. However, in addition to this theory, a second hypothesis has been put forward indicating that besides the extended life duration, ageing by itself could favour cancer, meaning that in addition to mutations induced by exogenous factors, ageing-related endogenous mutations could occur. Consequently, it has been postulated that the currently expanded ageing of the population could be per se a major cause of the observed increased incidence of cancer. It cannot be assumed that ageing by itself is a major contributing factor to cancer genesis for the following reasons: i) in tissue culture, there is no evidence showing that spontaneous (or induced) mutation rates increase according to the number of previous cell generations (123); ii) for a cell to mutate, it needs to divide (124). This basic observation is compulsory. Yet, the widely agreed observation is that the number of stem cells decreases with ageing. It follows thus to conceive that the probability of mutations may be lower in elderly people than in young people, although in the former, the total number of mutations can be higher due to the bioaccumulation process; iii) while it seems clear that ageing can be associated with physiological immunodeficiency and that, in general, immunodeficiency, be it innate or acquired, can favour virus-induced mutagenesis, there is no convincing experimental or clinical data suggesting that ageing per se can spur the initiation of cancers in elderly people. This means that, as much as ageing-related immunodeficiency may play a role in carcinogenesis due to a deficiency in the immunosurveillance system (role of $\mathrm{K}$ and NK cells), it would intervene in the promotion phase and not in the initiation phase. From these data, we conclude that ageing per se cannot be a factor, which contributes to initiate cancer, but rather, if we assume that many environmental factors are mutagenic, that cancer risk is clearly related to age, i.e. to duration of exposure to these factors.

Vulnerability of children with specific reference to fetus. Indeed, a basic observation that could argue against the previous considerations whereby age is a major contributing factor to the current cancer problem comes from the fact that the increasing cancer incidence is not restricted to any particular age group. Worldwide, age-specific rates of cancer incidence, i.e. the standardized rates for each age group in particular, are rising across the whole age spectrum and particularly in children and young adults. This is the case in the USA as in Europe. According to the NCI, the incidence rate increase for childhood cancers in the USA has been assessed on average at $1 \%$ yearly over the past 30 years and this $1 \%$ per year figure is also confirmed in Europe (125-127). However, in some countries, it can be higher. For example, in the UK, the overall rate of childhood, adolescent and young adult cancer incidence is increasing by $1.5 \%$ per annum (128-130). In Europe, about $1 \%$ of all malignant tumors arise in patients younger than 20 . Within this age group, the overall incidence rate over the last three decades have been increasing in all ages, but mainly in infants before the age of 3 and in adolescents after the age of 14 .

A major question deals with the causal origin of this increase. Considering the presumed role of environmental factors in childhood cancers, there are three periods during which exposures may take place: the preconceptional period (i.e. effects on parental germ cells), the prenatal period (i.e. exposure of the embryo or fetus via the mother's placenta) and the post-natal period which corresponds to the direct exposure of children to exogenous factors. Childhood exposure to chemicals may result in chemically-induced carcinogenesis as well as in virus-induced carcinogenesis, through chemicallyinduced immunosuppression. This could be particularly the case in infants, in whom contamination by immunosuppressive chemicals can enhance their physiological postnatal immunologic immaturity $(131,132)$. Infants and children differ also from adults in their direct exposure to environmental toxicants both qualitatively and quantitatively, because proportionally to body weight, they ingest relatively more water and food, and breathe more air than adults (133) and by specific physical activity close to the ground (134). In addition, the high rates of cell proliferation and differentiation as well as their lower capacity of cell detoxication and DNA reparation (135) render cells of the fetus and developing child more susceptible to mutations and/or epigenetic alterations (114). This explains why many clinical studies have demonstrated the extreme vulnerability of the fetus to environmental factors, including viruses (136-138), radiation (139), hormones and chemicals (140-143). Moreover, because there is no protective barrier between the developing fetus and its mother, trans-placental exposure of the fetus to natural or synthetic hormones and chemicals does occur (144-147). In addition, infants may be contaminated during breast-feeding (147). Numerous studies 
of prenatal exposure in animal models have confirmed the above observations, indicating that a causal link between environmental carcinogens and cancers exists (148-150). Considering the aetiology of cancer in children, parental exposure to carcinogens is indeed of critical importance. However, although maternal tobacco smoking during pregnancy was first suspected (151), it was not confirmed. There is no consistent association with childhood cancers overall or with specific types, no matter which exposure period is considered. Moreover, a similar negative trend has been put forward for maternal alcohol drinking $(152,153)$. By contrast paternal smoking (154) as well as paternal alcohol drinking before pregnancy (155) were revealed to be associated with a small increase of childhood cancers including acute lymphoid leukemia. This strongly suggests that exposure to classical lifestyle-related factors cannot explain the current growing incidence of childhood cancers, but that preconceptional paternal exposure to carcinogens may be relevant. An important finding, which accounts for the difficulty in interpreting epidemiological data of environmental carcinogenesis is the existence of a critical window period of fetal exposure, during which there is an increased risk of subsequent development of cancer. Based on experimental data, it can be hypothesized that through the perturbation of fetal organogenesis and cell differentiation, there could be a mechanism whereby in utero exposure to low levels of chemicals could lead to the development of several types of cancers, which may occur later in life $(156,157)$. Consequently, in addition to paternal smoking, prenatal exposure and even preconceptional paternal exposure to environmental carcinogens (158) may be causal factors accounting for the growing incidence of childhood cancers, as well as subsequent development of adult cancers.

Finally, contrary to the still prevailing current opinion stating that the growing incidence of cancer is related to classical lifestyle-related factors, improvement of screening tests and/or ageing of the population, we consider that three new concepts have recently emerged, which lead to the conclusion that the bulk of excess cancers in populations exposed to carcinogens, is from the exposure itself in the population at large and not from modification of a large excess risk in subgroups with specific genetic predisposition. The first new concept is that due to the extreme vulnerability of the fetus, in utero exposure to exogenous factors may result in the subsequent development of cancers $(159,160)$; the second one is that children are at high risk of cancer due to their specific physiological conditions (specifically during their prepubertal period) and their particular vulnerability to exogenous factors; the third one is that cancers in elderly people imply a phenomenon of mutational bioaccumulation, mainly related to duration of exposure to risk factors. Thus, the older a person is, the longer the exposure duration to these factors is and the higher the risk of developing cancer. According to several cancer registries, this seems particularly the case for people aged up to 80 years.

From this overview, we conclude that, lifestyle-related factors with the notable exception of tobacco smoking are not mutagenic, and that screening methods cannot fully account for the currently growing incidence of cancers so that this growing incidence of cancers may result in part from the emergence of new environmental factors. We therefore propose that the causal origin of many cancers cannot be restricted to lifestyle-related factors, but in addition to these factors, depends on many environmental factors including viruses, radiation and chemicals.

\section{References}

1. Shibuya K, Mathers CD, Boschi-Pinto C, Lopez AD and Murray CJ: Global and regional estimates of cancer mortality and incidence by site: II. Results for the global burden of disease. BMC Cancer 26: 37-62, 2002.

2. Stewart BW and Kleihues P: WHO World Cancer Report. IARC Press, Lyon, 2003.

3. Danaei G, Vander Hoorn S, Lopez AD, Murray CJ and Ezzati M: Causes of cancer in the world: comparative risk assessment of nine behavioural and environmental risk factors. Lancet 366 : 1784-1793, 2003.

4. Boyle P and Ferlay J: Cancer incidence and mortality in Europe, 2004. Ann Oncol 16: 481-488, 2005

5. Clapp RW, Howe GK and Jacobs M: Environmental and occupational causes of cancer re-visited. J Public Health Policy 27: 61-76, 2006.

6. Frankish H: 15 million new cancer cases per year by 2020 , says WHO. Lancet 361: 1278, 2003.

7. Harvard Center for Cancer Prevention: Harvard Report on Cancer Prevention. Volume 1, Causes of human cancer. Cancer Causes Control 7: S3-S59, 1996

8. Boffetta P: Involuntary smoking and lung cancer. Scand J Work Environ Health 28: 30-40, 2002.

9. Das SK: Harmful health effects of cigarette smoking. Mol Cell Biochem 253: 159-165, 2005.

10. Epstein SS: Environmental and occupational pollutants are avoidable causes of breast cancer. Int J Health Serv 24: 145-150, 1994.

11. Sasco AJ, Kaaks R and Little RE: Breast cancer: occurrence, risk factors and hormone metabolism. Expert Rev Anticancer Ther 3: 546-562, 2003

12. Belpomme D: La part de l'environnement physico-chimique dans la genèse des cancers: quelle amplitude et comment la mesurer? Bull Mem Acad R Med Belg 160: 163-180, 2005.

13. Newby JA and Howard CV: Environmental influences in cancer aetiology. J Nutr Env Med 15: 56-114, 2006.

14. Sasco AJ: Foreword. In: Reproductive Health and the Environment. Nicolopoulou-Stamati P, Hens L and Howard V (eds). Springer-Verlag, Heidelberg, ppXVII-XIX, 2007.

15. English D, Holman CDJ, Milne E, et al: The quantification of drug caused morbidity and mortality in Australia, 1995 edition. Commonwealth Department of Human Services and Health. AGPS, 1995

16. IARC: IARC Monographs on the evaluation of the carcinogenic risk of chemicals to humans. In: Tobacco Smoke and Involuntary Smoking. Vol. 83. IARC Press, Lyon, 2004.

17. Levi F: Cancer prevention: epidemiology and perspectives. Eur J Cancer 35: 1912-1924, 1999.

18. IARC: IARC Monographs on the evaluation of the carcinogenic risk of chemicals to humans. In: Alcohol Drinking. Vol. 44, IARC Press, Lyon, 1988.

19. Poschl G and Seitz HK: Alcohol and cancer. Alcohol Alcohol 39: 155-165, 2004.

20. Berenblum I: The cocarcinogenic action of croton resin. Cancer Res 1: 40, 1941.

21. Sarma DS, Rao PM and Rajalakshmi S: Liver tumour promotion by chemicals: models and mechanisms. Cancer Surv 5: 781-798, 1986.

22. McKillop IH and Schrum LW: Alcohol and liver cancer. Alcohol 35: 195-203, 2005.

23. Robin MA, Sauvage I, Grandperret T, Descatoire V, Pessayre D and Fromenty B: Ethanol increases mitochondrial cytochrome P450 2E1 in mouse liver and rat hepatocytes. FEBS Lett 579: 6895-6902, 2005.

24. Szabo G: Consequences of alcohol consumption on host defence. Alcohol Alcohol 34: 830-841, 1999.

25. Peterson DR: Alcohol, iron-associated oxidative stress and cancer. Alcohol 35: 243-249, 2005.

26. Block G, Patterson B and Subar A: Fruit, vegetables, and cancer prevention: a review of the epidemiological evidence. Nutr Cancer 18: 1-29, 1992. 
27. Weisburger JH: Lifestyle, health and disease prevention: the underlying mechanisms. Eur J Cancer Prev 11: S1-S7, 2002.

28. Cook LS, Goldoft M, Schwartz SM and Weiss NS: Incidence of adenocarcinoma of the prostate in Asian immigrants to the United States and their descendants. J Urol 161: 152-155, 1999.

29. Lacey JV Jr, Devesa SS and Brinton LA: Recent trends in breast cancer incidence and mortality. Environ Mol Mutagen 39: 82-88, 2002.

30. Le GM, Gomez SL, Clarke CA, Glaser SL and West DW: Cancer incidence patterns among Vietnamese in the United States and Ha Noi, Vietnam. Int J Cancer 102: 412-417, 2002.

31. Bartsch H and Nair J: Oxidative stress and lipid peroxidationderived DNA-lesions in inflammation driven carcinogenesis. Cancer Detect Prev 28: 385-391, 2004.

32. IARC: IARC Handbook of cancer prevention. Fruit and vegetables. Vol. 8, IARC Press, Lyon, 2003.

33. IARC: IARC Handbook of cancer prevention. In: Cruciferous vegetables. Vol. 9, IARC Press, Lyon, 2004.

34. Borek C: Dietary antioxidants and human cancer. Integr Cancer Ther 3: 333-341, 2004.

35. Kato J, Ikemoto A, Mizutani T: The effect of dietary fatty acids on the expression levels and activities of hepatic drug metabolizing enzymes. J Health Science 49: 105-114, 2003.

36. Knize MG, Salmon CP, Pais P and Felton JS: Food heating and the formation of heterocyclic aromatic amine and polycyclic aromatic hydrocarbon mutagens/carcinogens. Adv Exp Med Biol 459: 179-193, 1999.

37. Anderson KE, Sinha R, Kulldorff M, et al: Meat intake and cooking techniques: associations with pancreatic cancer. Mutat Res 30: 506-507,2002.

38. Turesky RJ: Interspecies metabolism of heterocyclic aromatic amines and the uncertainties in extrapolation of animal toxicity data for human risk assessment. Mol Nutr Food Res 49: 101-117, 2005

39. Mucci LA, Wedren S, Tamimi RM, Trichopoulos D and Adami HO: The role of gene-environment interaction in the aetiology of human cancer: examples from cancers of the large bowel, lung and breast. J Intern Med 249: 477-493, 2001.

40. Saadatian-Elahi M, Toniolo P, Ferrari P, Goudable J, Akhmedkhanov A, Zeleniuch-Jacquotte A and Riboli E: Serum fatty acids and risk of breast cancer in a nested case-control study of the New York University Women's Health Study. IARC Sci Publ 156: 227-230, 2002.

41. Kushi L and Giovannucci E: Dietary fat and cancer. Am J Med 113: S63-S70, 2002.

42. Prentice RL, Caan B, Chlebowski RT, et al: Low-fat dietary pattern and risk of invasive breast cancer: the Women's Health Initiative Randomized Controlled Dietary Modification Trial. JAMA 295: 629-642, 2006.

43. Potter JD: Nutrition and colorectal cancer. Cancer Causes Control 7: 127-146, 1996.

44. Gonzalez CA: The European Prospective Investigation into Cancer and Nutrition (EPIC). Public Health Nutr 9: 124-126, 2006

45. Dougherty CP, Henricks Holtz S, Reinert JC, Panyacosit L, Axelrad DA and Woodruff TJ: Dietary exposures to food contaminants across the United States. Environ Res 84: 170-185, 2000.

46. Trewavas A and Stewart D: Paradoxical effects of chemicals in the diet on health. Curr Opin Plant Biol 6: 185-190, 2003.

47. Simopoulos AP: Energy imbalance and cancer of the breast, colon and prostate. Med Oncol Tumor Pharmacother 7: 109-120, 1990.

48. IARC: IARC Handbook of cancer prevention. In: Weight Control and Physical Activity. Vol. 6. IARC Press, Lyon, 2002.

49. Calle EE, Rodriguez C, Walker-Thurmond $\mathrm{K}$ and Thun MJ: Overweight, obesity, and mortality from cancer in a prospectively studied cohort of USA adults. N Engl J Med 348: 1625-1638, 2003.

50. Rodriguez C, Patel AV, Calle EE, Jacobs EJ, Chao A and Thun MJ: Body mass index, height, and prostate cancer mortality in two large cohorts of adult men in the United States. Cancer Epidemiol Biomarkers Prev 10: 345-353, 2001.

51. Petrelli JM, Calle EE, Rodriguez C and Thun MJ: Body mass index, height, and postmenopausal breast cancer mortality in a prospective cohort of USA women. Cancer Causes Control 13: 325-332, 2001

52. Willett EV, Skibola CF, Adamson P, et al: Non-Hodgkin's lymphoma, obesity and energy homeostasis polymorphisms. Br J Cancer 93: 811-816, 2005.

53. Uauy R and Solomons N: Diet, nutrition, and the life-course approach to cancer prevention. J Nutr 135: S2934-S2945, 2005.
54. World Cancer Research Fund: Food, nutrition and the prevention of cancer: a global perspective. American Institute for Cancer Research. Washington DC, pp371-373, 1997.

55. Irigaray $\mathrm{P}$, Ogier $\mathrm{V}$, Jacquenet $\mathrm{S}$, et al: Benzo[a]pyrene impairs $\mathrm{b}$-adrenergic stimulation of adipose tissue lipolysis and causes weight gain in mice: a novel molecular mechanism of toxicity for a common food pollutant. FEBS J 273: 1362-1372, 2006.

56. Irigaray P, Mejean L and Laurent F: Behaviour of dioxin in pig adipocytes. Food Chem Toxicol 43: 457-460, 2005.

57. Hutcheon DE, Kantrowitz J, Van Gelder RN and Flynn E: Factors affecting plasma benzo[a]pyrene levels in environmental studies. Environ Res 32: 104-110, 1983.

58. Wester PW, Krajnc EI, van Leeuwen FX, Loeber JG, van der Heijden CA, Vaessen HA and Helleman PW: Chronic toxicity and carcinogenicity of bis(tri-n-butyltin)oxide (TBTO) in the rat. Food Chem Toxicol 28: 179-196, 1990.

59. Grun F, Watanabe H, Zamanian Z, et al: Endocrine-disrupting organotin compounds are potent inducers of adipogenesis in vertebrates. Mol Endocrinol 20: 2141-2155, 2006.

60. IARC: IARC Monographs on the evaluation of the carcinogenic risk of chemicals to humans. In: Combined Estrogen-progestogene Contraceptives and Combined Estrogen-progestogene Menopausal Therapy. Vol. 91, IARC Press, Lyon, 2006.

61. Doll R and Peto R: The causes of cancer: quantitative estimates of avoidable risks of cancer in the United States today. J Natl Cancer Inst 66: 1191-1308, 1981

62. Mackay J and Eriksen MP: The Tobacco Atlas. World Health Organization, Geneva, 2002.

63. Ezzati M and Lopez AD: Estimates of global mortality attributable to smoking in 2000. Lancet 362: 847-852, 2003.

64. Dockery DW, Pope CA, Xu X, et al: An association between air pollution and mortality in six US cities. N Engl J Med 329: 1753-1759, 1993.

65. Pope CA, Burnett RT, Thun MJ, et al: Lung cancer, cardiopulmonary mortality, and long-term exposure to fine particulate air pollution. JAMA 287: 1132-1141, 2002.

66. Cohen AJ: Air pollution and lung cancer: what more do we need to know? Thorax 58: 1010-1012, 2003.

67. IARC: IARC Monographs on the evaluation of the carcinogenic risk of chemicals to humans. In: Hepatitis Viruses. Vol. 59, IARC Press, Lyon, 1994.

68. Cougot D, Neuveut C and Buendia MA: HBV induced carcinogenesis. J Clin Virol 34: S75-S78, 2005.

69. Harris CC and Sun TT: Interactive effects of chemical carcinogens and hepatitis B virus in the pathogenesis of hepatocellular carcinoma. Cancer Surv 5: 765-780, 1986

70. Ozturk M: Genetic aspects of hepatocellular carcinogenesis. Semin Liver Dis 19: 235-242, 1999.

71. Dinse GE, Umbach DM, Sasco AJ, Hoel DG and Davis DL: Unexplained increases in cancer incidence in the United States from 1975 to 1994: possible sentinel health indicators? Annu Rev Public Health 20: 173-209, 1999.

72. Edwards BK, Brown ML, Wingo PA, et al: Annual report to the nation on the status of cancer, 1975-2002, featuring populationbased trends in cancer treatment. J Natl Cancer Inst 97: 1407-1427, 2005.

73. Sasco AJ: Epidemiology of breast cancer: an environmental disease? APMIS 109: 321-332, 2001.

74. National Cancer Institute, DCCPS, Surveillance Research Program, Cancer Statistics Branch. Surveillance, Epidemiology, and End Results (SEER) Program (www.seer.cancer.gov), SEER Cancer Statistics Review (CSR) 1975-2001: http://seer.cancer.gov/csr/ 1975 2002/.

75. Post PN, Stockton D, Davies TW and Coebergh JW: Striking increase in incidence of prostate cancer in men aged $<60$ years without improvement in prognosis. Br J Cancer 79: 13-17, 1999.

76. Hodgson NC, Button J and Solorzano CC: Thyroid cancer: is the incidence still increasing? Ann Surg Oncol 11: 1093-1097, 2004.

77. Eden K, Mahon S and Helfand M: Screening high-risk populations for thyroid cancer. Med Pediatr Oncol 36: 583-591, 2002.

78. Solomon D: Chapter 14: Role of triage testing in cervical cancer screening. J Natl Cancer Inst Monogr pp97-101, 2003.

79. Crawford ED: Epidemiology of prostate cancer. Urology 62: 3-12, 2003.

80. Parkin DM and Fernandez LM: Use of statistics to assess the global burden of breast cancer. Breast J 12: S70-S80, 2006.

81. Bray F, Loos AH, McCarron P, et al: Trends in cervical squamous cell carcinoma incidence in 13 European countries: changing risk and the effects of screening. Cancer Epidemiol Biomarkers Prev 14: 677-686, 2005. 
82. Harmer C, Staples M and Kavanagh AM: Evaluation of breast cancer incidence: is the increase due entirely to mammographic screening? Cancer Causes Control 10: 333-337, 1999.

83. Stenman UH, Abrahamsson PA, Aus G, et al: Prognostic value of serum markers for prostate cancer. Scand J Urol Nephrol (Suppl) 216: 64-81, 2005.

84. Botha JL, Bray F, Sankila R and Parkin DM: Breast cancer incidence and mortality trends in 16 European countries. Eur J Cancer 39: 1718-1729, 2003.

85.Olsen O and Gotzsche PC: Cochrane review on screening for breast cancer with mammography. Lancet 358: 1340-1342, 2001.

86.Zahl PH, Gotzsche PC, Andersen JM and Maehlen J: Results of the Two-County trial of mammography screening are not compatible with contemporaneous official Swedish breast cancer statistics. Dan Med Bull 53: 438-440, 2006.

87.IARC: IARC Handbook of cancer prevention. In: Breast Cancer Screening. Vol. 7, IARC Press, Lyon, 2002.

88.IARC: IARC Handbook of cancer prevention. In: Cervix Cancer Screening. Vol. 10, IARC Press, Lyon, 2005.

89. Coleman MP: Trends in breast cancer incidence, survival, and mortality. Lancet 356: 590-591, 2000.

90. Oliver SE, Gunell D and Donovan JL: Comparison of trends in prostate cancer mortality in England and Wales and the USA. Lancet 355: 1788-1789, 2000.

91.Loeb KR and Loeb LA: Significance of multiple mutations in cancer. Carcinogenesis 21: 379-285, 2000

92 Hahn WC and Weinberg RA: Modelling the molecular circuitry of cancer. Nat Rev Cancer 2: 331-341, 2002.

93. Hoyer AP, Gerdes AM, Jorgensen T, Rank F and Hartvig HB: Organochlorines, p53 mutations in relation to breast cancer risk and survival. A Danish cohort-nested case-controls study. Breast Cancer Res Treat 71: 59-65, 2002.

94. Lichtenstein P, Holm NV, Verkasalo PK, et al: Environmental and heritable factors in the causation of cancer - analyses of cohorts of twins from Sweden, Denmark and Finland. N Engl J Med 342: 78-85, 2000.

95. Czene K, Lichtenstein P and Hemminki K: Environmental and heritable causes of cancer among 9.6 million individuals in the Swedish Family - Cancer Database. Int J Cancer 99: 260-266, 2002.

96. Penn I: Occurrence of cancers in immunosuppressed organ transplant recipients. Clin Transpl 00: 147-158, 1998.

97. Jensen P, Hansen S, Moller B, et al: Skin cancer in kidney and heart transplant recipients and different long-term immunosuppressive therapy regimens. J Am Acad Dermatol 40: 177-186, 1999.

98. Hunt SA: Malignancy in organ transplantation: heart. Transplant Proc 34: 1874-1876, 2002.

99. Euvrard S, Kanitakis J and Claudy A: Skin cancers after organ transplantation. N Engl J Med 348: 1681-1691, 2003.

100.Inskip PD: Thyroid cancer after radiotherapy for childhood cancer. Med Pediatr Oncol 36: 568-573, 2001.

101. Wakeford R: The cancer epidemiology of radiation. Oncogene 23: 6404-6428, 2004.

102. Frisch M, Biggar RJ, Engels EA and Goedert JJ: AIDS-Cancer Match Registry Study Group. Association of cancer with AIDSrelated immunosuppression in adults. JAMA 285: 1736-1745, 2001.

103. Schulte PA: The role of genetic factors in bladder cancer. Cancer Detect Prev 11: 379-388, 1988.

104. Vogelstein B and Kinzler KW: The Genetic Basis of Human Cancer. McGraw-Hill Companies, Inc., New York, 1998.

105. Burt RW, Bishop DT, Lynch HT, Rozen P and Winawer SJ: Risk and surveillance of individuals with heritable factors for colorectal cancer. WHO Collaborating Centre for the Prevention of Colorectal Cancer. Bull World Health Organ 68: 655-665, 1990.

106. Weitzel JN, Ding S, Larson GP, et al: The HRAS1 minisatellite locus and risk of ovarian cancer. Cancer Res 60: 259-261, 2000.

107. King MC, Marks JH and Mandell JB: New York Breast Cancer Study Group: breast and ovarian cancer risks due to inherited mutations in BRCA1 and BRCA2. Science 302: 643-646, 2002.

108. Muller A and Fishel R: Mismatch repair and the hereditary non-polyposis colorectal cancer syndrome (HNPCC). Cancer Invest 20: 102-109, 2002.

109. Ponz de Leon M, Benatti P, Borghi F, et al: Aetiology of colorectal cancer and relevance of monogenic inheritance. Gut 53: 115-122, 2004.
110. De Vita VT, Hellman S and Rosenberg SA: Cancer: Principles and Practice of Oncology. Vol. 1, 5th edition. Lippincott-Raven Publisher, Philadelphia, 2004.

111. Baker SG and Kaprio J: Common susceptibility genes for cancer: search for the end of the rainbow. BMJ 332: 1150-1152, 2006.

112. Birch JM: Genes and cancer. Arch Dis Child 80: 1-3, 1999.

113. Taningher M, Malacarne D, Izzotti A, Ugolini D and Parodi S: Drug metabolism polymorphisms as modulators of cancer susceptibility. Mutat Res 436: 227-261, 1999.

114.Perera FP: Environment and cancer: who are susceptible? Science 278: 1068-1073, 1997.

115. Ershler WB and Longo DL: The biology of aging: the current research agenda. Cancer 80: 1284-1293, 1997.

116. Moller H: Trends in incidence of testicular cancer and prostate cancer in Denmark. Hum Reprod 16: 1007-1011, 2001.

117. Jemal A, Thomas A, Murray T and Thun M: Cancer statistics, 2002. CA Cancer J Clin 52: 23-47, 2002.

118. Jemal A, Murray T, Samuels A, Ghafoor A, Ward E and Thun MJ: Cancer statistics, 2003. CA Cancer J Clin 53: 5-26, 2003.

119. Camplejohn RS, Gilchrist R, Easton D, et al: Apoptosis, ageing and cancer susceptibility. Br J Cancer 88: 487-490, 2003.

120. Cancer Research UK, CancerStats incidence-UK, April 2003: http://www.cancerresearchuk.org'

121. Cancer Research UK, CancerStats incidence-UK, February 2004. http://www.cancerresearchuk.org/aboutcancer/statistics/statsmi $\mathrm{sc} / \mathrm{pdfs} /$ cancerstats/incidence.pdf.

122. Armitage P and Doll R: The age distribution of cancer and a multistage theory of carcinogenesis. Br J Cancer 8: 1-12, 1954.

123. Bell E, Marek LF, Livinstone DS, et al: Loss of division potential in vitro: aging or differentiation? Science 102: 1158$1163,1978$.

124.Knudson AG: Antioncogenes and human cancer. Proc Natl Acad Sci USA 90: 10914-10921, 1993

125. Steliarova-Foucher E, Stiller C, Kaatsch P, et al: Geographical patterns and time trends of cancer incidence and survival among children and adolescents in Europe since the 1970s (the ACCIS project): an epidemiological study. Lancet 364: 2097-2105, 2004.

126. Kaatsch P, Steliarova-Foucher E, Crocetti E, Magnani C, Spix C and Zambon P: Time trends of cancer incidence in European children (1978-1997): report from the Automated Childhood Cancer Information System project. Eur J Cancer 42: 1961-1971, 2006.

127. Dreifaldt AC, Carlberg M and Hardell L: Increasing incidence rates of childhood malignant diseases in Sweden during the period 1960-1998. Eur J Cancer 40: 1351-1360, 2004.

128. Birch JM, Alston RD and Kelsey AM: Classification and incidence of cancers in adolescents and young adults in England 1979-1997. Br J Cancer 87: 1267-1274, 2002.

129. Stiller C: Epidemiology of cancer in adolescents. Med Pediatr Oncol 39: 149-155, 2002.

130. McNally RJQ, Alexander FE and Birch JM: Space-time clustering analyses of childhood and acute lymphoblastic leukaemia by immunophenotype. Br J Cancer 87: 513-515, 2002.

131. Weisglas-Kuperus N, Patandin S, Berbers GA, et al: Immunologic effects of background exposure to polychlorinated biphenyls and dioxins in Dutch preschool children. Environ Health Perspect 108: 1203-1207, 2000.

132. Ten Tusscher GW, Steerenberg PA, van Loveren $\mathrm{H}$, et al: Persistent hematologic and immunologic disturbances in 8year-old Dutch children associated with perinatal dioxin exposure. Environ Health Perspect 111: 1519-1523, 2003.

133. Roberts RJ: Overview of similarities and differences between children and adults: implications for risk assessment. In: Similarities and Differences between Children and Adults. Guzelian PS, Henry CJ and Olin SS (eds). ILSI Press, Washington, DC, pp11-15, 1992.

134. Carroquino MJ, Galson SK, Licht J, et al: The USA EPA Conference on Preventable Causes of Cancer in Children: a research agenda. Environ Health Perspect 106: 867-873, 1998.

135.Perera FP, Tang D, Tu YH, Cruz LA, Borjas M, Bernert T and Whyatt RM: Biomarkers in maternal and newborn blood indicate heightened fetal susceptibility to procarcinogenic DNA damage. Environ Health Perspect 112: 1133-1136, 2004.

136. Avgil $\mathrm{M}$ and Ornoy A: Herpes simplex virus and Epstein-Barr virus infections in pregnancy: consequences of neonatal or intrauterine infection. Reprod Toxicol 21: 436-445, 2006.

137. De Jong EP, De Haan TR, Kroes AC, Beersma MF, Oepkes D and Walther FJ: Parvovirus B19 infection in pregnancy. J Clin Virol 36: 1-7, 2006. 
138. Ornoy A and Tenenbaum A: Pregnancy outcome following infections by coxsackie, echo, measles, mumps, hepatitis, polio and encephalitis viruses. Reprod Toxicol 21: 446-457, 2006.

139.Zahm SH and Devesa SS: Childhood cancer: overview of incidence trends and environmental carcinogens. Environ Health Perspect 103: 177-184, 1995.

140.Perera FP, Illman SM, Kinney PL, et al: The challenge of preventing environmentally related disease in young children: community-based research in New York City. Environ Health Perspect 110: 197-204, 2002.

141. Nielsen SS, Mueller BA, De Roos AJ, Viernes HM, Farin FM and Checkoway $\mathrm{H}$ : Risk of brain tumors in children and susceptibility to organophosphorus insecticides: the potential role of paraoxonase (PON1). Environ Health Perspect 113: 909913, 2005.

142. Bradman A and Whyatt RM: Characterizing exposures to nonpersistent pesticides during pregnancy and early childhood in the National Children's Study: a review of monitoring and measurement methodologies. Environ Health Perspect 113 1092-1099, 2005

143. Menegaux F, Baruchel A, Bertrand Y, et al: Household exposure to pesticides and risk of childhood acute leukaemia. Occup Environ Med 63: 131-134, 2006.

144. Davis DL, Axelrod D, Bailey L, Gaynor M and Sasco AJ: Rethinking breast cancer risks and the environment: the case for the precautionary principle. Environ Health Perspect 106: 523-529, 1998 .

145. Anderson LM, Diwan BA, Fear NT and Roman E: Critical windows of exposure for children's health: cancer in human epidemiological studies and neoplasms in experimental animal models. Environ Health Perspect 108: 573-594, 2000.

146. Dolk H and Vrijheid M: The impact of environmental pollution on congenital anomalies. Br Med Bull 68: 25-45, 2003.

147. Sharpe RM and Irvine DS: How strong is the evidence of a link between environmental chemicals and adverse effects on human reproductive health? BMJ 328: 447-451, 2004.

148. Skakkebaek NE, Rajpert-De Meyts E and Main KM: Testicular dysgenesis syndrome: an increasingly common developmental disorder with environmental aspects. Hum Reprod 16: 972-978, 2001.

149. Von Ehrenstein OS, von Mutius E, Maier E, et al: Lung function of school children with low levels of alpha1-antitrypsin and tobacco smoke exposure. Eur Respir J 19: 1099-1106, 2002.
150. Tsuda H, Naito A, Kim CK, Fukamachi K, Nomoto H and Moore MA: Carcinogenesis and its modification by environmental endocrine disruptors: in vivo experimental and epidemiological findings. Jpn J Clin Oncol 33: 259-270, 2003.

151. Boffetta P, Tredaniel J and Greco A: Risk of childhood cancer and adult lung cancer after childhood exposure to passive smoke: a meta-analysis. Environ Health Perspect 108: 73-82, 2000.

152. Sorahan T, Lancashire R, Prior P, Peck I and Stewart A: Childhood cancer and parental use of alcohol and tobacco. Ann Epidemiol 5: 354-359, 1995.

153.Petridou E, Trichopoulos D, Kalapothaki V, et al: The risk profile of childhood leukaemia in Greece: a nationwide casecontrol study. Br J Cancer 76: 1241-1247, 1997.

154. Sorahan T, McKinney PA, Mann JR, et al: Childhood cancer and parental use of tobacco: findings from the inter-regional epidemiological study of childhood cancer (IRESCC). Br J Cancer 84: 141-146, 2001.

155. Infante-Rivard C, Krajinovic M, Labuda D and Sinnett D: Childhood acute lymphoblastic leukemia associated with parental alcohol consumption and polymorphisms of carcinogenmetabolizing genes. Epidemiology 13: 277-281, 2002.

156. Vom Saal FS, Timms BG, Montano MM, et al: Prostate enlargement in mice due to fetal exposure to low doses of estradiol or diethylstilbestrol and opposite effects at high doses. Proc Natl Acad Sci USA 94: 2056-2061, 1997.

157. Ma X, Buffler PA, Gunier RB, et al: Critical windows of exposure to household pesticides and risk of childhood leukemia. Environ Health Perspect 110: 955-960, 2002.

158. Colt JS and Blair A: Parental occupational exposures and risk of childhood cancer. Environ Health Perspect 106: 909-925, 1998.

159. Hardell L, Bavel B, Lindstrom G, Eriksson M and Carlberg M: In utero exposure to persistent organic pollutants in relation to testicular cancer risk. Int J Androl 29: 228-234, 2006.

160. Hardell L, van Bavel B, Lindstrom G, et al: Increased concentrations of polychlorinated biphenyls, hexachlorobenzene, and chlordanes in mothers of men with testicular cancer. Environ Health Perspect 111: 930-934, 2003.

161. Ledermann S: Alcool, alcoolisme et alcoolisation. Cahier de Ined, Ined-PUF, 26, 1956.

162. Nizard A: Les effets sur la mortalité de quelques maux contemporains: sida, hépatite, alcool et tabac. Population 55: 503-564, 2000 . 